\title{
O extrato bruto hidroalcoólico das folhas de Piper caldense C. DC. na redução do consumo de álcool em ratos.
}

\author{
PEREIRA, R.'; GUEDES, A.2; DA SILVA, G.E. ** \\ 1 Departamento de Ciências Farmacêuticas, Laboratório de Farmacologia, Universidade Regional de Blumenau \\ (FURB), R. São Paulo 2171, 89030-000, Blumenau - SC, Brasil *gefarmaco@hotmail.com; ² Departamento de \\ Ciências Farmacêuticas, Laboratório de Farmacognosia, Universidade Regional de Blumenau (FURB), R. São \\ Paulo 2171, 89030-000, Blumenau - SC, Brasil
}

\begin{abstract}
RESUMO: A investigação de plantas medicinais como recurso terapêutico para combater o alcoolismo ainda é muito insipiente com poucas espécies investigadas. No presente trabalho avaliamos o efeito do extrato hidroalcoólico das folhas da planta Piper caldense C. DC. com relação ao consumo de álcool e também a sua potencialidade ansiolítica. Foram utilizados ratos Wistar machos, os quais foram divididos em grupos controle (solução fisiológica) e tratado (extrato da planta nas doses de 25, 50 e $150 \mathrm{mg} / \mathrm{kg}$, e diazepam $2 \mathrm{mg} / \mathrm{kg}$ ). Os animais foram tratados através da via intraperitoneal $1 \mathrm{~h}$ antes dos experimentos. Os modelos animais utilizados foram: Labirinto em Cruz Elevado (LCE) e auto-administração de álcool (AA). No LCE o extrato não apresentou efeito ansiolítico do tipo benzodiazepínico. Por outro lado, no comportamento relacionado a auto-administração de solução de álcool, o extrato apresentou efeito significativo reduzindo o consumo de álcool em relação ao grupo controle. Apesar do extrato não ter apresentado efeito ansiolítico, o mesmo parece apresentar potencialidades para combater o abuso e a dependência de álcool.
\end{abstract}

PALAVRAS-CHAVE: Piper caldense C. DC., labirinto em cruz elevado, auto-administração de álcool.

\begin{abstract}
The hydroalcoholic extract of leaves of Piper caldense C. DC. decreases alcohol consumption in rats. The investigation of medicinal plants as therapeutic resources in the combat of alcoholism is still very incipient with few species being investigated. The purpose of the present study was to examine the effects of the hydroalcoholic extract of leaves of Piper caldense C. DC. in relation to alcohol consumption and also its anxiolytic potentiality. Male Wistar rats, which had been separated into control group (saline) and treated group (Plant extract doses of 25,50 and $150 \mathrm{mg} / \mathrm{kg}$ and $2 \mathrm{mg} / \mathrm{kg}$ of diazepam), were used. Animals were injected intraperitoneally $1 \mathrm{~h}$ before the tests. The following models were used: Elevated plus maze (EPM) and alcohol self-administration (ASA). In the EPM, the extract did not show benzodiazepine anxiolytic effect. On the other hand, in the behavior related to alcohol self-administration, the extract showed a significant effect, reducing alcohol consumption compared to the control group. Although the extract has not shown any anxiolytic effect, the results suggest that the plant has potential to combat alcohol abuse and addiction.
\end{abstract}

Key words: Piper caldense C. DC., elevated plus maze, alcohol self-administration.

\section{INTRODUÇÃO}

A busca por novos fármacos que possam combater o alcoolismo é um desafio constante tendo rendido até o momento três fármacos clinicamente bem estabelecidos, dissulfiram (Suh et al., 2006), naltrexona (Johnson B.A., 2008) e acamprosato (Mason \& Heyser, 2010). Mesmo assim, a eficácia destes medicamentos é relativa (Popova et al., 2011), portanto a busca por outros fármacos é fundamental. Um campo a ser explorado é o das plantas medicinais, como este é muito amplo, uma maneira de delimitá-lo é estudar plantas que apresentam alguma ação sobre o sistema nervoso central ou, mais especificamente, combatem algum transtorno psiquiátrico, e verificar a potencialidade com relação ao consumo do álcool. Entre as plantas com comprovada ação central estão a Kava-kava, 
Piper methysticum G. Forster, usada para combater a ansiedade (Pittler \& Ernest, 2000; Sarris et al., 2009) e a Erva de São João, Hypericum perforatum L., usada como antidepressivo (Deltito \& Beyer, 1998; Kasper et al., 2010). Esta última é a que apresenta mais estudos investigando a potencialidade no combate ao alcoolismo através de estudos préclínicos em ratos. Rezvani e colaboradores (1999) testaram o efeito do Hypericum perforatum em duas linhagens de ratos e demonstraram que o extrato foi capaz de reduzir o consumo de álcool. Em outro estudo, realizado por De Vry e colaboradores (1999), em linhagem de ratos que preferem álcool cAA, também foi mostrada uma redução do consumo de álcool. Quanto a Piper methysticum, nenhum artigo científico, até o momento, demonstrou ação no sentido de reduzir o consumo do álcool. Talvez a inexistência esteja relacionada aos efeitos deletérios que esta planta pode trazer ao fígado (Teschke, 2010), órgão tão destacado na biotransformação do álcool. Assim sendo, evitando uma abordagem com uma espécie que pode apresentar toxidade hepática e o fato da planta não ser encontrada naturalmente no Brasil, o presente trabalho investigou a potencialidade de uma outra espécie, pois há mais de 280 espécies de piperáceas nas matas brasileiras (Figueiredo \& Sazima, 2000). A espécie escolhida foi a Piper caldense C. DC, conhecida popularmente como pimenta d'água, a qual apresenta poucos dados na literatura e que é usada popularmente na Paraíba como antídoto para picada de cobra e como sedativo (Cardozo Jr \& Chaves, 2003). O fato dos efeitos desta planta ainda não terem sido investigados em modelos animais de ansiedade e consumo de álcool, impulsionaram o presente trabalho.

\section{MATERIAL E MÉTODOS}

\section{Animais}

Foram utilizados 69 ratos Wistar machos, pesando em torno de $300 \mathrm{~g}$ cada, com idade de aproximadamente 3,0 meses, provenientes do Biotério Central da Universidade Regional de Blumenau. Os animas foram mantidos sob um sistema claro/escuro de $12 \mathrm{~h}$ (período claro a partir das 07:00 h), com temperatura controlada de $23 \pm$ $2^{\circ} \mathrm{C}$, comida (ração comercial) e água à vontade. O presente estudo foi aprovado pelo Comitê de Ética na Experimentação com Animal (CEEA) com o protocolo $n^{\circ}$ 012/2007.

\section{Drogas}

Utilizou-se extrato bruto das folhas da planta Piper caldense $(25 \mathrm{mg} / \mathrm{kg}, 50 \mathrm{mg} / \mathrm{kg}, 150 \mathrm{mg} /$ $\mathrm{kg}$ ), diazepam (2 mg/kg) e solução fisiológica
( $\mathrm{NaCl}$ 0,9\%). O extrato bruto foi diluído em solução fisiológica ( $\mathrm{NaCl} 0,9 \%$ ), contendo $1,0 \%$ de Tween 80. O diazepam foi preparado a partir de uma ampola Válium $\circledast$, laboratório Roche $(10 \mathrm{mg} / 2 \mathrm{~mL}$, ampola), o qual foi diluído em solução fisiológica ( $\mathrm{NaCl} 0,9 \%$ ) contendo 1,0\% de Tween 80 . As drogas foram administradas através da via intraperitoneal (i.p.) num volume de $1 \mathrm{ml} / \mathrm{kg}$.

O material vegetal foi coletado no Parque Municipal São Francisco de Assis. A exsicata encontra-se depositada no Herbário da Universidade Regional de Blumenau, Dr. Roberto Miguel Klein, $n^{\circ} 2207$. Com relação à preparação do extrato, as folhas coletadas foram separadas e submetidas à secagem a $40^{\circ} \mathrm{C}$ em estufa com circulação de ar. Após a secagem, o material foi moído (Ming, 1966; Falkenberg et al., 1999). O extrato vegetal foi obtido através de maceração em etanol. Após a filtração, o extrato foi concentrado em evaporador rotatório a vácuo e encaminhado aos ensaios farmacológicos.

\section{Modelos Experimentais Labirinto em Cruz Elevado (Da Silva et al., 2005)}

O modelo é feito de madeira e possui quatro braços elevados (52 cm de altura) com $50 \mathrm{~cm}$ de comprimento e $10 \mathrm{~cm}$ de largura. Os braços estão dispostos perpendicularmente, com dois braços opostos fechados por paredes de $40 \mathrm{~cm}$ de altura e dois braços abertos, tendo em sua intersecção uma plataforma central $(10 \times 10 \mathrm{~cm})$ que dá acesso a qualquer um dos quatro braços.

\section{Auto-administração de álcool (Da Silva et al., 2005) \\ Consiste em gaiolas individuais de arames} com comedouro e com suporte para 2 bebedouros $(100 \mathrm{ml})$. As garrafas são cheias com líquidos, em geral um bebedouro contém água e o outro, solução de álcool. A estante onde ficaram expostas as gaiolas fica no biotério setorial e a luminosidade segue o mesmo esquema do biotério, ou seja, luz acesa às 07:00h e desligada às 19:00h.

\section{Procedimentos Labirinto em Cruz Elevado}

Os animais foram divididos em 5 grupos, com 5 a 8 animas cada: solução salina, Extrato bruto de Piper caldense 25, 50 e $150 \mathrm{mg} / \mathrm{kg}$ ou diazepam $2 \mathrm{mg} / \mathrm{kg}$, administrados via i.p.. Uma hora após a administração da droga, cada animal foi exposto ao modelo individualmente. Os animais foram observados por um período de $5 \mathrm{~min}$. e os efeitos do tipo ansiolítico foram definidos como um aumento na proporção de entradas nos braços abertos e o tempo gasto nos braços abertos relativo ao total de tempo gasto em ambos os braços. O número total 
de entradas nos braços fechados foi utilizado como uma medida da atividade locomotora (Prediger et al., 2006).

\section{Auto-administração de álcool}

Os animais foram divididos em 4 grupos, com 7 animais cada: solução fisiológica e extrato bruto de Piper caldense C. DC. (25, 50 e $150 \mathrm{mg} /$ $\mathrm{kg}$ ), administrados através da via i.p.. Os animais foram colocados em gaiolas individuais com acesso a comida e água, inicialmente em duas garrafas. Após um período de três dias de habituação, uma das garrafas teve a água substituída por solução de álcool com diferentes concentrações, conforme o esquema: $1^{\circ}$ ao $4^{\circ}$ dia, $2 \% ; 5^{\circ}$ ao $8^{\circ}$ dia, $4 \% ; 9^{\circ}$ ao $12^{\circ} \mathrm{dia}, 6 \% ; 13^{\circ}$ ao $16^{\circ}, 8 \%$. Durante o período de exposição ao álcool, os animais foram tratados com as drogas, conforme o grupo, $1 \mathrm{~h}$ antes da fase escura do ciclo. Todos os dias no começo da manhã eram medidos o consumo de água e de álcool. Dois parâmetros foram avaliados, o consumo de álcool em $\mathrm{g} / \mathrm{kg}$ e a porcentagem de preferência ao álcool [volume de solução de álcool consumido/consumo total de líquido (água + solução de álcool) x 100].

\section{Análise estatística}

Os resultados obtidos foram analisados pelo software Statistica (Versão 6.0). Todos os dados foram apresentados na forma de gráficos expressos como média \pm E.P.M.. Conforme o tipo de experimento, foi utilizado a análise de variância (ANOVA) de uma ou duas vias. A comparação múltipla post hoc foi realizada através do teste de Newman-Keuls. O nível de significância foi de 5\%.

\section{RESULTADOS}

No labirinto em cruz elevado (LCE) (Figura 1), a análise de variância (ANOVA) de uma via detectou efeito significante para o tratamento no parâmetro tempo nos braços abertos $\left(F_{4,32}=2,63\right.$, $p<0,05)$ e número de entradas nos braços abertos $\left(F_{4,32}=2,66, p<0,05\right)$, expressos em porcentagem; Entretanto, a significância detectada está relacionada ao controle positivo diazepam, o qual demonstrou efeito ansiolítico em relação ao controle, solução salina (em ambos os parâmetros a análise post hoc, teste de Newman-Keuls, demonstrou uma significância de $p<0,02)$. Assim sendo, os grupos tratados com as diferentes doses de extrato bruto da planta Piper caldense, não demonstraram efeito do tipo ansiolítico. Com relação ao parâmetro, número de entradas nos braços fechados, não foram encontradas diferenças significantes $\left(F_{4,32}=0,58\right.$, $p<0,67)$. Desta forma, não houve prejuízo locomotor em nenhum dos tratamentos.
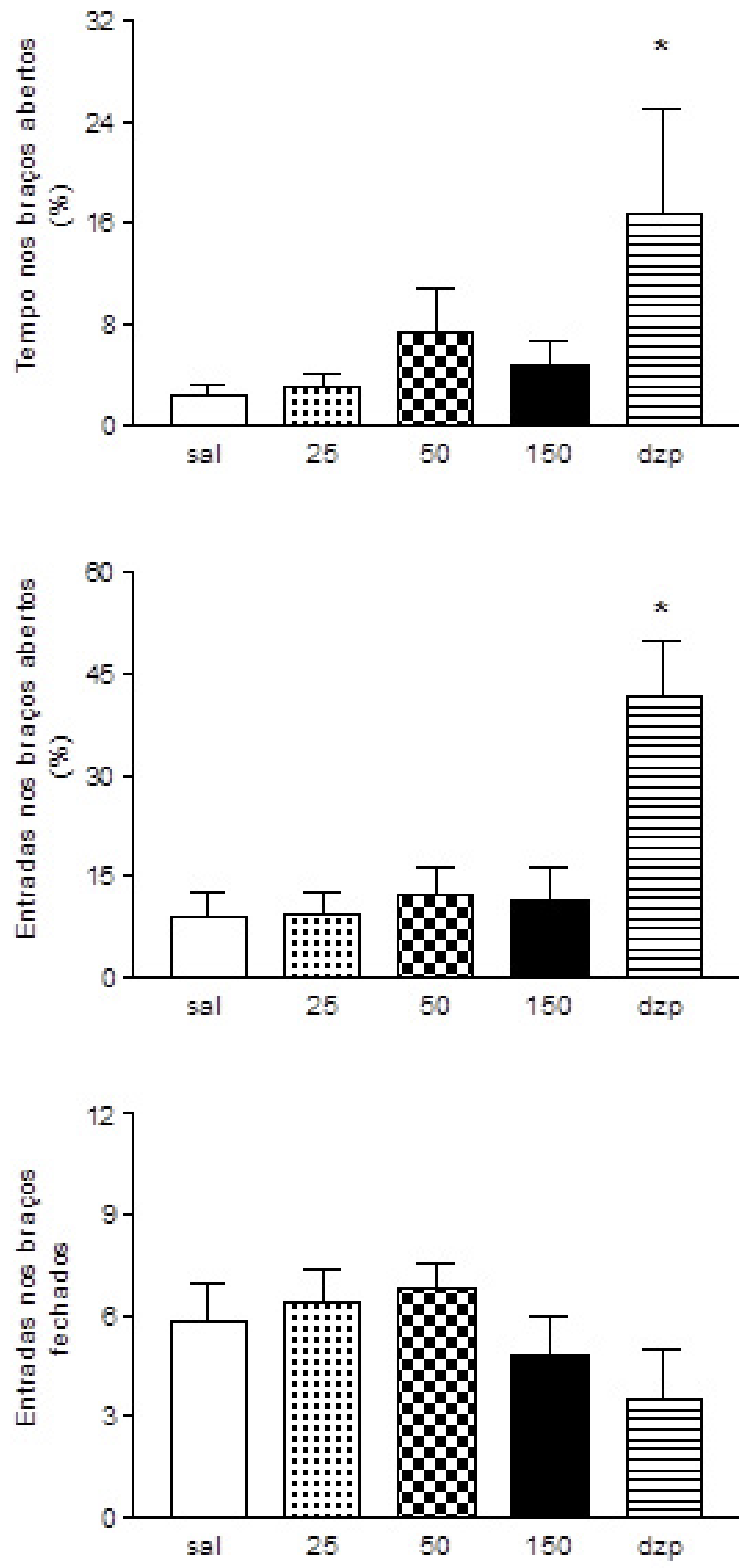

FIGURA 1. Porcentagem de tempo nos braços abertos [(tempo no aberto/tempo total) x 100], porcentagem de entradas nos braços abertos [(entradas no aberto/total de entradas) $\times 100] \mathrm{e}$ número de entradas nos braços fechados no labirinto em cruz elevado. Os tratamentos foram: solução fisiológica $0,9 \%$ (sal), o extrato bruto das folhas da planta Piper caldense nas doses de 25, 50 e 150 $\mathrm{mg} / \mathrm{kg}(25,50$ e 150) e diazepam $2 \mathrm{mg} / \mathrm{kg}$ (dzp), sendo as administrações realizadas através da via i.p. $1 \mathrm{~h}$ antes da exposição ao modelo. As barras representam as médias \pm EPM para grupos de 5-8 animais. * Diferença significativa comparado com o respectivo grupo controle, salina (ANOVA de uma via seguida pelo teste de Newman-Keuls). 
Por fim, o efeito do extrato de Piper caldense foi analisado no modelo de auto-administração de álcool. Neste modelo efeitos significantes foram encontrados para todos os parâmetros avaliados. Primeiramente, no parâmetro consumo de álcool (Figura 2), ANOVA de duas vias detectou efeito significante para o fator tratamento $\left(F_{3,27}=13,62\right.$, $p<0,00001)$, dia $\left(F_{15,405}=3,78, p<0,00001\right)$ e interação dia tratamento $\left(F_{45,405}=1,40, p<0,05\right)$. Convém destacar que a análise post hoc (teste de NewmanKeuls) do tratamento demonstrou efeito significante para todas as doses do extrato: $25 \mathrm{mg} / \mathrm{kg}(\mathrm{p}<0,0003)$, $50 \mathrm{mg} / \mathrm{kg}(\mathrm{p}<0,0002)$ e $150 \mathrm{mg} / \mathrm{kg}(\mathrm{p}<0,0002)$. Assim, a faixa de dose testada foi eficaz em reduzir o consumo da solução de álcool. Além do consumo de álcool, foi analisado a preferência a esta solução em relação à água. ANOVA de duas vias detectou efeito significante para o fator tratamento $\left(F_{3,27}=14,67\right.$, $p<0,00001)$ e dia $\left(F_{15,405}=9,71, p<0,00001\right)$. Para a interação dia tratamento não foi encontrado efeito significante $\left(F_{45,405}=0,94, p<0,58\right)$. Como ocorreu para o consumo de álcool, aqui também as diferentes doses do extrato demonstraram ter efeito significante(teste de Newman-Keuls), $25 \mathrm{mg} /$ $\mathrm{kg}(\mathrm{p}<0,0002), 50 \mathrm{mg} / \mathrm{kg}(\mathrm{p}<0,0002)$ e $150 \mathrm{mg} / \mathrm{kg}$ $(\mathrm{p}<0,0001)$.

\section{DISCUSSÃO}

A avaliação do extrato bruto da planta Piper caldense não apresentou efeito ansiolítico em ratos testados no labirinto em cruz elevado (LCE). Entretanto, no modelo de auto-administração de álcool os animais tratados com o extrato mostraram uma redução tanto no consumo quanto na preferência à solução de álcool.

Para a avaliação do efeito ansiolítico de drogas, um dos modelos animais mais usados é o LCE (Corbett et al., 1991; Lapmanee et al., 2012). Este modelo experimental baseia-se no conflito entre a tendência inata à exploração de um ambiente novo e a aversão a lugares altos e desprotegidos (File, 1995), situação mimetizada neste labirinto. A espécie Piper methysticum (Pittler \& Ernest, 2000) é a piperaceae mais investigada com relação aos seus efeitos ansiolíticos. Rex e colaboradores (2002), observaram efeito ansiolítico em ratos que receberam extrato bruto obtido a partir das raízes de Piper methysticum e expostos ao LCE. Por outro lado, a administração do extrato de folhas de Piper amalago L. e Piper mikanianum (Kunth) Steudel apresentou um efeito ansiogênico nos animais (Lopes et al., 2012). É importante ressaltar que estes são os dois únicos trabalhos encontrados na literatura, até o momento, testando o extrato de espécies diferentes do gênero Piper em ratos e avaliando-os no LCE. Os dois trabalhos citados mostraram que, embora as espécies de plantas sejam do mesmo gênero e poderiam apresentar compostos químicos em comum, os efeitos obtidos foram opostos. Particularmente, no presente trabalho, nenhum dos dois efeitos, ansiolítico ou ansiogênico, ficou demonstrado para a Piper caldense. Uma diferença importante entre o estudo da Piper methysticum (Rex et al., 2002) e o realizado por Lopes e colaboradores (2012) está relacionado a parte da planta utilizada. O primeiro utilizou a raiz e o segundo folhas da planta. Mesmo que as espécies alvo do estudo pudessem ter os mesmos compostos químicos, a concentração é diferenciada nas folhas, caule e raiz. No trabalho desenvolvido em nossos laboratórios o extrato da Piper caldense, foi obtido a partir das folhas da planta, o motivo principal para esta escolha levou em consideração o local de coleta, Parque Municipal, e o impacto ambiental. No caso de usar a raiz como fonte, a população da planta é reduzida. A escolha não invalida o estudo, pois nas folhas de plantas do gênero Piper vários compostos podem ser encontrados, como é o caso do alcalóide pipermatistina, em maior quantidade nas folhas e em menor quantidade no caule e raiz (Smith, 1979). O contrário ocorre com as kavalactonas, compostos aos quais são atribuídos propriedades ansiolíticas (Davies et al., 1992) e estão presentes em menor quantidade nas folhas, e em maior quantidade nas raízes (Lebot \& Levesque, 1989). Outros aspectos a destacar foram as doses e a via de administração. No presente estudo, as doses ficaram próximas do trabalho de Rex e colaboradores (2002) com outra espécie de piper a Piper methysticum, os quais administraram por via oral em ratos $120 \mathrm{e}$ $240 \mathrm{mg} / \mathrm{kg}$ do extrato bruto. A não utilização das mesmas doses levou em consideração a via de administração, intraperitoneal, a qual apresenta maior biodisponibilidade. Em trabalho realizado por Baum e colaboradores (1998) a administração intraperitoneal de $120 \mathrm{mg} / \mathrm{kg}$ do extrato de Kavakava, foi considerada uma dose elevada pelos autores, embora os mesmo tenham testados também uma dose de $220 \mathrm{mg} / \mathrm{kg}$. Um ultimo aspecto está relacionado a solubilidade do extrato bruto, doses superiores a $150 \mathrm{mg} / \mathrm{kg}$ do extrato das folhas de Piper caldense não apresentavam solubilidade adequada para administração intraperitoneal limitando a avaliação de potencialidades ansiolíticas para doses superiores as testadas.

O efeito de drogas sobre o consumo do álcool normalmente é avaliado utilizando o modelo animal de duas garrafas. Neste modelo, os animais são colocados em gaiolas individuais e têm a oportunidade de consumir água ou uma solução de álcool em concentrações que, normalmente, estão na faixa de 2 a 20 \% (Da Silva 

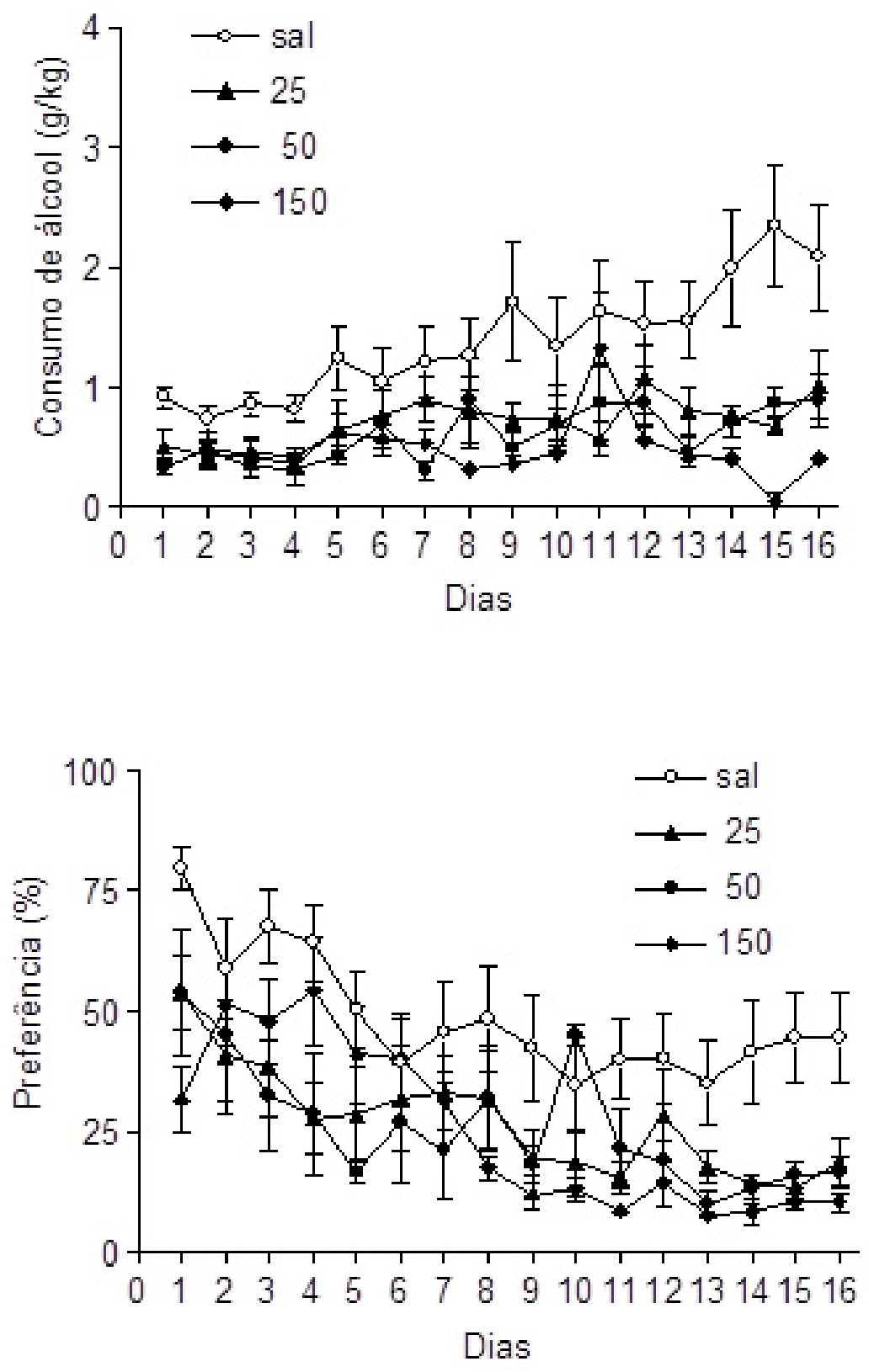

FIGURA 2. Comparação do consumo de álcool, expresso em gramas de álcool absoluto consumido diariamente por quilo de peso animal, e preferência ao álcool, como porcentagem de mililitros de álcool consumido/total de líquido consumido para diferentes tratamentos: solução fisiológica $0,9 \%$ (sal) e o extrato bruto das folhas da planta Piper caldense de 25, 50 e 150 mg/kg (25, 50 e 150). As administrações foram realizadas através da via i.p. As concentrações de álcool mudavam a cada 4 dias: $1^{\circ}$ ao $4^{\circ}$ dia, $2 \%$; $5^{\circ}$ ao $8^{\circ}$ dia, $4 \%$; $9^{\circ}$ ao $12^{\circ}, 6 \%$ e $13^{\circ}$ ao $16^{\circ}, 8 \%$. Cada ponto representa a média \pm EPM para grupos de 8 animais.

et al., 2005; Simms et al., 2010). Com relação às investigações que utilizam extratos de plantas, há poucos estudos aprofundados, embora o uso e efeitos de plantas com relação ao álcool, em humanos, já tenham sido relatados ao redor do planeta com uma variedade grande de espécies (Liu et al., 2011; Tomczyk et al., 2012). A respeito de avaliações do efeito do extrato de plantas de uma mesma espécie no consumo de álcool em animais experimentais podem ser citados uso de Hipericum perforatum nas linhagens Fawn-Hooded e High Alcohol Drinking (Rezvani et al., 1999) e Strychnos nux-vomica em ratos da linhagem Charles Foster (Sukul et al., 2001). Há outros trabalhos, entretanto os compostos de plantas foram isolados e só então administrados, como por exemplo, o realizado por Keung e Vallee (1993), onde daidzina e daidzeina obtidos da Radix pueraria foram administrados em 
Hamster Syrian Golden. Além destes, há aqueles que fizeram o uso de um preparado de diversas plantas como, por exemplo, a administração de uma mistura indiana chamada SKV em ratos Wistar (Shanmugasundaram e Shanmugasundaram, 1986). Nos estudos citados ficou demonstrado uma redução do consumo de solução de álcool. Entretanto, em todos estes trabalhos o mecanismo envolvido não foi completamente elucidado, os autores enfatizam que mais estudos devem ser realizados. Vale destacar que em revisão realizada por Rezvani e colaboradores (2003), são descritos várias investigações focalizando três plantas Hypericum perforatum, Radix pueraria e Tabernanthe iboga. Mesmo assim, os autores também destacam a necessidade de aprofundar os estudos. Apesar das várias espécies citadas, não há nenhum estudo mostrando que plantas do gênero Piper são capazes de reduzir o consumo de álcool. Apenas um trabalho que avaliou a potencialidade da Piper methysticum como agente para reduzir a vontade incontrolável pela droga (Steiner, 2001), nesta abordagem experimental, um estudo piloto com uma quantidade padronizada de kavapirona reduziu os sinais de abstinência em alcoolistas. $O$ próprio autor considerou os resultados apenas como indicativos do potencial da planta, portanto, mais um estudo com necessidade de aprofundamento.

No presente trabalho, foi investigado se o extrato teria alguma propriedade ansiolítica, pois segundo a hipótese da redução de tensão (Cappell e Herman, 1972) o consumo de álcool poderia ser fomentado pela ansiedade, assim, quando esta é reduzida o consumo de álcool poderia sofrer influência e diminuir. Apesar de não ter sido encontrado efeito ansiolítico, ocorreu a redução do consumo e da preferência do álcool. Desta forma, não foi possível fazer a relação entre efeito ansiolítico e redução do consumo de álcool.

Como já destacado em estudos prévios (Krystal et al, 2006; Vengeliene et al., 2008; Trigo et al., 2010, Pascual et al., 2009) o sistema GABAérgico , dopaminérgico, opioidérgico e glutamatérgico são os prováveis candidatos envolvidos no consumo e dependência de álcool. Neste sentido, ao menos para dois sistemas, há uma relação com a clínica, pois as duas drogas que atuam no sistema nervoso central no combate ao alcoolismo, naltrexona e acamprosato, atuam bloqueando receptor opióide e glutamatérgico, respectivamente (Johnson B.A., 2008; Mason \& Heyser, 2010). O trabalho realizado, não contou com estudos fitoquímicos, isolando compostos, e nem neuroquímicos, assim, não é possível confirmar o envolvimento dos sistemas citados anteriormente. Além disso, efeito periférico, como aquele que ocorre com o dissulfiram, inibição enzimática, também pode estar envolvido.
O trabalho apresentado avaliou o efeito do extrato de uma planta presente nas matas brasileiras, a Piper caldense, na auto-administração de álcool. Embora não tenham sido investigados os mecanismos envolvidos na redução do consumo e preferência ao álcool, o presente estudo revelou uma propriedade em potencial de Piper caldense, que pode ser empregada no combate ao abuso do álcool, um importante problema na nossa sociedade.

Estudos fitoquímicos, envolvendo o isolamento de compostos do extrato bruto das folhas da planta devem ser realizados, bem como, farmacológicos no sentido de elucidar os possíveis mecanismos envolvidos no efeito "antiálcool".

\section{AGRADECIMENTOS}

A Fundação Municipal do Meio Ambiente (Faema), da cidade de Blumenau-SC, por permitir a coleta da planta no Parque Municipal São Francisco de Assis. A professora Mirele Titton Calderari John do Departamento de Ciências Farmacêuticas da Universidade Regional de Blumenau, pela ajuda na coleta e identificação da planta. A FURB pelo apoio financeiro através de bolsa PIBIC/FURB.

\section{REFERÊNCIAS}

BAUM, S.S.; HILL, R.; ROMMELSPACHER, H. Effect of kava extract and individual kavapyrones on neurotransmitter levels in the nucleus accumbens of rats. Progress in Neuropsychopharmacology and Biological Psychiatry. v.22, p.1105-1120, 1998.

CAPPELL, H.; HERMAN, C.P. Alcohol and tension reduction. Quartely Journal of Studies on Alcohol, v.33, p.33-64, 1972.

CARDOZO JUNIOR, E. L.; CHAVES, M. C. O. Caldensin, a new natural n-methylaristolactam from Piper Caldense. Pharmaceutical Biology, v.41, p.216-218, 2003.

CORBETT, R. et al. GABAmimetic agents display anxiolytic-like effects in the social interaction and elevated plus maze procedures. Psychopharmacology, v.104, p.312-316, 1991.

DA SILVA, G.E.; VENDRUSCOLO, L.F.; TAKAHASHI, R.N. Effects of ethanol on locomotor and anxiety-like behaviors and the acquisition of ethanol intake in Lewis and spontaneously hypertensive rats. Life Sciences, v.77, p.693-706, 2005.

DAVIES, L.P. et al. Kavapyrones and resin: studies on $\mathrm{GABA}_{A}, \mathrm{GABA}_{\mathrm{B}}$, and benzodiazepine binding sites in rodent brain. Pharmacology and Toxicology, v. 71, p.120-126, 1992.

DELTITO, J.; BEYER, D. The scientific, quasi-scientific and popular literature on the use of St. John's Wort in the treatment of depression. Journal of Affective Disorders. v.5, p.345-351, 1998.

DE VRY, J. et al. Comparison of hypericum extracts with imipramine and fluoxetine in animal models of depression and alcoholism. European Neuropsychopharmacology, v.9, p.461-468, 1999.

Rev. Bras. PI. Med., Campinas, v.17, n.1, p.157-163, 2015. 
FALKENBERG, M.B.; SANTOS, R.I.; SIMÕES, C.M.O. Introdução à análise fitoquímica. In: SIMÕES, C.M.O. et al. (Org.). Farmacognosia: da planta ao medicamento. Florianópolis/Porto Alegre: Editora da UFSC/Editora da UFRGS, 1999. p. 163-179.

FIGUEIREDO, R. A.; SAZIMA, M. Pollination biology of Piperaceae species in southeastern Brazil. Annals of Botany, v.85, p.455-460, 2000.

FILE, S.E. Animal models of different anxiety states. In: BIGGIO, G.;SANNA, E.; COSTA, E.; GABA Receptors and Anxiety: From Neurobiology to treatment. Raven Press. New York, 1995, p.93-113.

JOHNSON, B.A. Update on neuropharmacological treatments for alcoholism: scientific basis and clinical findings. Biochemical Pharmacology, v.75, p.34-56, 2008.

KASPER, S. et al. Efficacy and tolerability of Hypericum extract for the treatment of mild to moderate depression. European Neuropsychopharmacology, v.20, p.747765, 2010.

KEUNG, W.M., VALLEE, BL. Daidzin and daidzein suppress free-choice ethanol intake by syrian golden-hamsters. Proceedings Of The National Academy Of Sciences Of The United States Of America, v.90, p.10008$10012,1993$.

KRYSTAL, J.H. et al. Gamma-aminobutyric acid type A receptor and alcoholism: intoxication, dependence, vulnerability, and treatment. Archives of General Psychiatry, v. 63, p.957-968, 2006.

LAPMANEE, S. et al. Anxiolytic-like actions of reboxetine, venlafaxine and endurance swimming in stressed male rats. Behavioural Brain Research, v.231, p.20-28, 2012.

LEBOT, V.; LEVESQUE, J. The origin and distribution of kava (Piper methysticum Frost. f. and Piper wichmanii C. DC., Piperaceae) a phytochemical approach, Allertonia, v.5, p.223-280, 1989.

LIU, Q.; LAWRENCE, A.J.; LIANG, J.H. Traditional Chinese medicine for treatment of alcoholism: from ancient to modern. The American Journal of Chinese Medicine, v.39, p.1-13, 2011.

LOPES, J.J. et al. Neurobehavioral and toxicological activities of two potentially CNS-acting medicinal plants of Piper genus. Experimental and Toxicologic Pathology, v.64, p.9-14, 2012.

MASON, B.J.; HEYSER, C.J. Acamprosate: a prototypic neuromodulator in the treatment of alcohol dependence. CNS Neurological Disorders Drug Targets, v.9, p.2332, 2010.

MING, L.C. Coleta de plantas medicinais. In: DI STASI, L.C. (org.) Plantas medicinais: arte e ciência. Um guia para estudo interdisciplinar. São Paulo: Editora da Unesp, 1996. p. 69-86.

PASCUAL, M. et al. Repeated alcohol administration during adolescence causes changes in the mesolimbic dopaminergic and glutamatergic systems and promotes alcohol intake in the adult rats. Journal Neurochemistry, v. 108, p.920-931, 2009.

PITTLER, M.H.; ERNST, E. Efficacy of kava extract for treating anxiety: systematic review and meta-analysis.
Journal Clinical Psychopharmacology, v.20, p.8489, 2000.

POPOVA, S. et al. A literature review of cost-benefit analyses for the treatment of alcohol dependence. International Journal of Environmental Research and Puplic Health, v.8, p.3351-3364, 2011.

PREDIGER, R.D.S. et al. Activation of adenosine $A_{1}$ receptors reduces anxiety-like behavior during acute ethanol withdrawal (hangover) in mice. Neuropsychopharmacology, v.1, p.1-11, 2006.

REZVANI, A.H. et al. Attenuation of alcohol intake by extract of Hypericum perforatum (St. John's Wort) in two different strains of alcohol-preferring rats. Alcohol and Alcoholism, v.34, p.699-705, 1999.

REZVANI, A.H. et al. Plant derivatives in the treatment of alcohol dependency. Pharmacology Biochemistry and Behavior, v.75, p.593-606, 2003.

REX, A.; MORGENSTERN, E.; FINK, H. Anxiolytic-like effects of kava-kava in the elevated plus maze test- a comparison with diazepam. Progress in Neuropsychopharmacology and Biological Psychiatry. v.26, p.855-860, 2002.

SARRIS, J. et al. The Kava Anxiety Depression Spectrum Study (KADSS): a randomized, placebo-controlled crossover trial using an aqueous extract of Piper methysticum. Psychopharmacology v.205, p.399407, 2009.

S H A N M U G A S N D A R A M, E.R. B . ; SHANMUGASUNDARAM, K.R. An Indian herbal formula (SKV) for controlling voluntary ethanol intake in rats with chronic alcoholism. Journal of Ethnopharmacology, v.17, p.171-182, 1986.

SIMMS, J.A. et al. Long-Evans rats acquire operant selfadministration of $20 \%$ ethanol without sucrose fading. Neuropsychopharmacology, v.35, p.1453-1463, 2010.

SMITH, R. M. Pipermethystine, A novel pyridine alkaloid from Piper methysticum. Toxicology v.35, p.437-439, 1979.

STEINER, G.G. Kava as an Anticraving Agent: Preliminary Studies. Pacific Health Dialog, v.8, p.335-9, 2001.

SUH, J.J. et al. The status of dissulfiram: a half of a century later. Journal of Clinical Psychopharmacology, v.26, p.290-302, 2006.

SUKUL, N.C. et al. Strychnos nux-vomica extract and its ultra-high dilution reduce voluntary ethanol intake in rats. Journal of Alternative and Complementary Medicine, v.7, p.187-193, 2001.

TESCHKE, R. Kava hepatotoxicity--a clinical review. Annals of Hepatology, v.9, p.251-65, 2010.

TOMCZYK, M.; ZOVKO-KONCIC, M.; CHROSTEK, L. Phytoterapy of alcoholism, Natural Product Communications, v.7, p.273-280, 2012.

TRIGO, J.M. et al. The endogenous opioid system: A common substrate in drug addiction. Drug and Alcohol Dependence, v.108, p.183-194, 2010.

VENGELIENE, V. et al. Neuropharmacology of alcohol addiction. British Journal of Pharmacology, v.154, 299-315, 2008. 